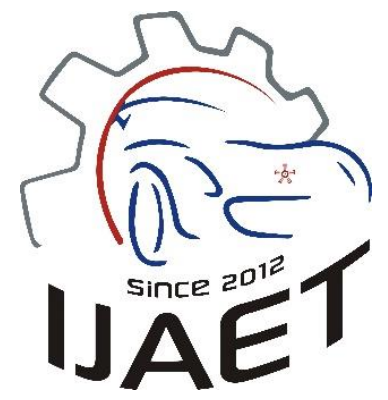

e-ISSN: 2146 - 9067

International Journal of Automotive

Engineering and Technologies

journal homepage: http://ijaet.academicpaper.org

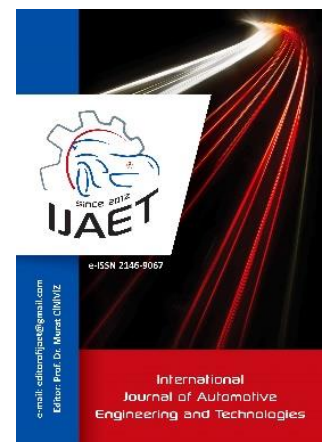

Original Research Article

\title{
Fuzzy logic controller for semi active suspension based on magneto-rheological damper
}

hosted by

Jurkish

\author{
Kazima Sosthene ${ }^{1 *}$, Musabyimana Josee ${ }^{2}$, Xiong Hui ${ }^{1}$ \\ Wuhan University of technology, Automotive school, Wuhan, China \\ University of Rwanda, college of science and technology, Rwanda
}

\author{
ARTICLE INFO \\ * Corresponding author \\ kazima10@gmail.com \\ Received: October 20, 2017 \\ Accepted: January 08, 2018 \\ Published by Editorial Board \\ Members of IJAET \\ (C) This article is distributed by \\ Turk Journal Park System \\ under the CC 4.0 terms and \\ conditions.
}

\begin{abstract}
With the increasing demand of the drive safety and ride comfort of vehicles, various new technologies are being applied in vehicle suspension system. In this case, the magnetorheological damper can adjust the damping dynamically, and fuzzy logic controller development to track the desired damping force is possible. The combination of two will effectively improve the suspension performance. Thereafter, a model built in Simulink is composed by road model, quarter vehicle model, Magneto Rheological damper model based on Bouc Wen model, damper coil current controller model and Fuzzy logical controller to track the desired damping force. The results obtained from road models have been used in combined simulation model. Finally, the comparative simulation experiments of passive suspension and semi-active suspension with magneto rheological damper was performed. The results show that, the ride comfort of quarter car model has been improved $10 \%$ compared to passive suspension; and vehicle stability $30 \%$ respectively.
\end{abstract}

Keywords: Semi-active suspension, Modified Bouc Wen Model, Fuzzy logic controller

\section{Introduction}

Suspension of vehicle is the part of vehicle which plays an important role of limiting the vibration between vehicle body and wheels; it is constituted by shock assimilator (damper), springs and the connector which links body and wheels. Suspension systems offers to the vehicle a big contribution in the vehicle's road handling, a good safety in braking, driving enjoyment and provide to occupants a comfort while driving in bad road situation where bumps, potholes, road crack or any other road disturbance situation presented, it serves in isolation of road vibration and protection of vehicle chassis and freight [1]. It provides also a protection to the vehicle itself and any payload from damage. The objectives of suspension are generally compromising; the setting of suspensions implies finding the right compromise. The road holding remains the necessity of vehicle suspension because all forces acting on vehicle pass through the tires and its components as well as the ride comfort. Different types of suspension have been developed and applied in vehicle but the tradeoff between road handling and comfort remain a big challenge for the automotive era. In the early 1970's, semi-active suspension systems have been investigated and studied where the tradition spring element is remained in this kind of suspension; however, the shock absorber damper is replaced with an adjustable 
and controllable damper. Meanwhile an active suspension system requires an external energy source to activate an actuator which is controls and monitoring the vehicle. The semi-active suspension dampers adjust their damping force in real time according to a controller strategy which is often based on the system dynamics. By adjusting the damper's fluid resistance movement, or damping coefficient which results on changing of the damping force behavior. The implementation of semi-active control law is based on real time adjustment of damping force. Nowadays, many semi-active dampers are using hydraulic or electromagnetic systems. Some researchers like Jorge de-J Lozoya-Santos, et al. [2] in their paper; Evaluation of on-off semiactive vehicle suspension systems by using the hardware-in-the-loop approach and the software-in-the-loop approach published in 2014, they investigated different control strategies of semi active suspension and they found that using 3 controllers, skyhook, ground hook and mixed sensor controller can greatly improve the ride comfort and road handling. Quanmin Guo et al. [3] (Guo and Hua, 2015) in their paper Intelligent Control of Vehicle Magneto-Rheological Semi-Active Suspension, the investigated on the neuro fuzzy PID control strategy, and the results showed an improvement of ride comfort as well as road holding. Generally, the intelligent suspension control is being expanded worldwide. In this paper a second law of Newton for the quarter car model and IF-THEN rules of fuzzy logic controller has been developed in Matlab/ Simulink. The results of simulation are suspension deflection, body dynamic behavior which are index of ride comfort and vehicle stability.

\section{Modelling and Simulation of Semi Active Suspension}

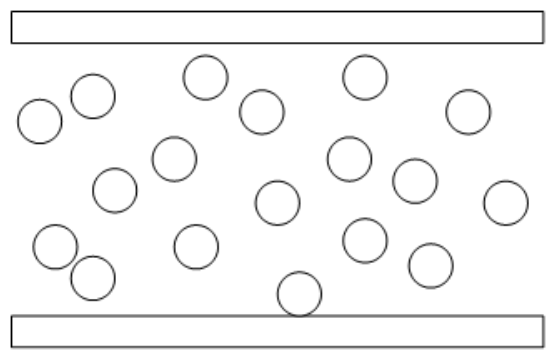

(a) Without Magnetic Field

\subsection{Magneto-rheological damper}

Magneto-rheological (MR) materials are classified in smart materials, they are presently being applied many applications. Smart materials are the materials which physical properties can be adjusted or changed by external physical properties such as, temperature, $\mathrm{pH}$, moisture, stress, electric or magnetic fields. Magneto-rheological material has various forms of fluids; it can be a gel or even a solid material like elastomers. A magneto-rheological fluid mainly composed by micron-sized iron element that is immerged in carrier oil. It presents the capacity of varying from free-moving liquid state into a semi-solid condition with limited fluid movement in fast response within some milliseconds when applied to the external magnetic field. As it said above their viscosity varies in little time which is less than ten milliseconds. In 1940s Jacob Rabinow [4] invented the fluid, which yield stress and viscosity changes when magnetic field is applied on it; since its invention different applications using MR fluid have been investigated and designed such as dampers, clutches, engine mounts, haptic devices and building dampers, etc. Physical characteristics changes of MR fluid are resulted from the chainlike structures between paramagnetic MR particles in the low permeability solvent [5]. At the normal state, MR fluid presents the isotropic Newtonian behavior because the MR particles move freely as shown in Fig. 1 (a). However, when the magnetic field is subjected to the MR fluid, MR fluid forms a chain structure as it is indicated in Fig. 1(b), MR fluids present the anisotropic Bingham behavior which result on resisting on flow and external shear stress. From this property, force or torque of application devices can be easily monitored by the density of magnetic field.

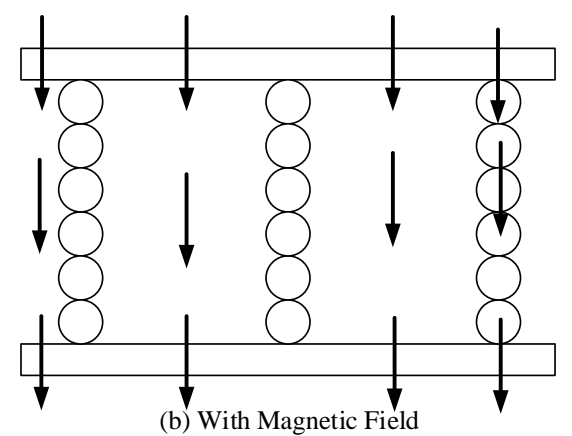

Figure 1. Magneto-rheological fluid 


\subsubsection{Mechanical model of MR damper}

MR dampers are called semi-active elements of suspension systems whose damping specifications may be changed in real time based on its ability of changing the viscosity of MR fluid as well its resistance to circulate due to magnetic field applied on it. The benefit of MR fluid is that can permit the changes in the damping force by varying the current subjected to the damper. Thereby the hysteretic model characteristics of MR damper are based on current dependent and a function of excitation amplitude. It is important to analyze and model the MR damper with appropriate methods in order to predict it behavior in various magnetic fields or excitations.

\subsubsection{Bingham model}

This Bingham model investigates, study plastic characteristic and the behavior of magnetorheological and electro rheological fluids. Bingham model ensure that a body remain as solid till a little yield stress is surpassed then after its shows a linear relationship between the stress and the rate of shear deformation. Some researchers like Stanway et al [6]. Investigated a mechanical model based on the Bingham plastic model to exhibits the MR damping system. As it indicated in Fig.2 the model is based on a combination between coulomb frictions and viscous dashpot. and is always utilized to analyze the characteristic or behavior of MR dampers [7].

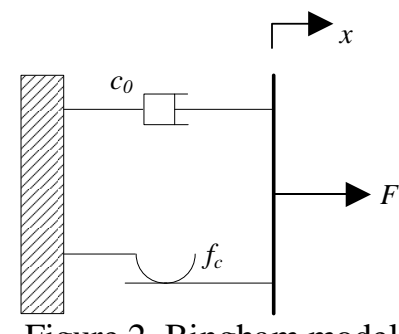

Figure 2. Bingham model

The force provided by mechanical element setting is coming from equilibrium concepts; it is expressed in the equation below:

$F(t)=c_{0} \dot{x}+f_{c} \operatorname{sgn}(\dot{x})+f_{0}$

Where, $c_{0}$ denoted as constant of damping coefficient, $\dot{x}$ defines the velocity of the external excitation $f_{c}$ denoted the frictional force and $f_{0}$ is the force offset related with the availability of an accumulator considering that this element has linear behavior and low stiffness. To investigate the flow of fluid, this mathematic expression model can be derived.

\subsubsection{Bouc-Wen model}

The hysteresis Bouc-Wen equation is among different models and the most used to study and simulate various method of expanding the damping system by changing the hysteresis. It has been invented by Bouc in 1971 [8] and later developed by Wen in 1976 [9] who has showed different methodologies of this model to show a wide kind of hysteretic patterns. According to this interesting behavior, the model was utilized to analyze different nonlinear hysteretic systems like MR damper and hysteretic isolators. However, MR dampers show a good typical behavior, the final hysteretic setting relies on certain particular specification features related to accumulator, damper geometry and so, on. Thus, the model should be suitable to have the real MR damper characteristic. As, it is indicated in the Fig. 3, the simple Bouc-Wen model is composed by three elements: a spring, a Bouc-Wen block and dashpot, mounted a parallel setting.

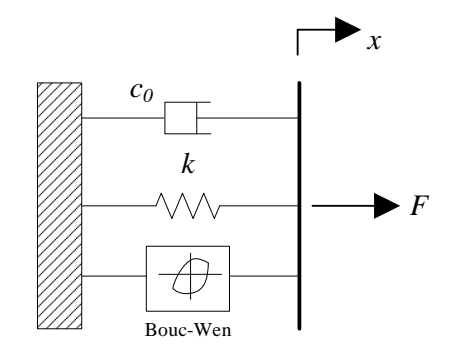

Figure 3. Bouc-wen model

The model above has been reused by Spencer et al. (1997) [10] and it investigates different characteristics of MR damper by comparing the performance of this model with other parametric models. Based to mechanical setting indicated in Fig. 3, the equation below expresses the damping force.

$F(t)=c_{0} \dot{x}+k\left(x-x_{0}\right)+\alpha z$

Where $c_{0}$ denoted the constant of viscous coefficient, $k$ denoted the constant of stiffness coefficient and $z$ is an evolutionary related variable with Bouc-Wen block and it ruled by:

$\dot{z}=-\gamma|\dot{x}| z|z|^{n-1}-\beta \dot{x}|z|^{n}+A \dot{x}$

$\mathrm{x}_{0}$ is denoted the displacement at initial state, which permit the presence accumulator in the 
mechanism system. Constant $c_{0}, k, \alpha, \beta, \gamma, A$ and $n$ are generally and the Bouc-Wen shape parameters or behaviors. They are the functions of the current subjected to the MR damper, frequency of vibration and amplitude. Nonlinear shape hysteretic curve can be controlled by varying the amounts of the Bouc-Wen block parameters permitting to monitor the smoothness in the state of transition between pre yield and post yield. Based to the ability to take the hysteretic element of the MR damper characteristics, the classic Bouc-Wen model is considered best rational model of mathematical and numerical simulation compare to Bingham model. The use of Bouc-Wen hysteric model, lead on a good simulation of MR damper, test and implementation of its parameters.

\subsubsection{Modified Bouc-Wen model}

As indicated in the Fig.4, the modified BoucWen model is made by adding spring and dashpot, hence $f$ defines the output damping force of magneto-rheological damper, $c_{1}$ denotes viscous damping coefficient at low velocity, $k_{0}$ is spring stiffness coefficient at high velocity, $c_{0}$ is viscous damping at high speed, $k_{l}$ is stiffness of shock absorber, $x$ is relative displacement of spring (i.e, relative displacement of sprung mass and unsprung mass), $x_{0}$ is initial relative displacement.

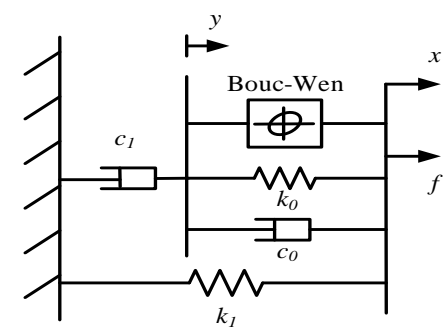

Figure 4. Bouc-Wen model

$f=c_{1} \dot{y}+k_{1}\left(x-x_{0}\right)$

$\dot{z}=-y|\dot{x}-\dot{y}| z|z|^{n-1}-\beta(\dot{x}-\dot{y})|z|^{n}+$ $A(\dot{x}-\dot{y})$

Where $z$ is denoted as evolution variable, is scale factor of Bouc-Wen hysteresis. Operator, $\gamma, \beta, A$, are correlation coefficients of hysteresis parameters, $n$ is index coefficient, typically is 2 .

$\dot{y}=\left[\alpha z+c_{0} \dot{x}+k_{0}(x-y)\right] /\left(c_{0}+c_{1}\right)$

$y$ is denoted as internal displacement, parameters $c_{0}, k_{0}, k l, x_{0}, \gamma, \beta, A$ and $\mathrm{n}$ are constant coefficient, parameters $\alpha$ and $c_{1}$ are functions of input current. Through curve fitting with linear function according to experimental data (table 1) [11].

$\left\{\begin{array}{c}c_{1}=c_{1 a}+c_{1 b} i \\ \alpha=\alpha_{b}+\alpha_{b} i\end{array}\right.$

The model of modified Bouc-Wen MR model is developed in simulink based on equations 4,5,6 and 7 as indicated in fig. 5 .

The simulation process was carried out with a sinusoidal frequency of $5 \mathrm{~Hz}$ and amplitude of $10 \mathrm{~mm}$ of displacement for a specific current applies repeating this process for every parameter combination. The responses of the MR damper for the variable input current simulation are indicated in Fig.6. In this case: the MR damper response was obtained by varying the input current while the amplitude and frequency are kept constant. On Fig.7, damping force versus displacement, the damping force increased along with the input current value applied on MR damper and the hysteretic characteristic is increased as shown in Fig.8. If the damper is operating without input current, the damper response shows a reduced hysteretic loop while operating with a non-zero constant input current level, the damper represents a huge important hysteretic characteristic. As the input current is increased, the magnetic field to which the MR fluid is subjected is also increasing and thus the mechanical properties of the fluid are varied, particularly the yield force that provokes a plastic-like characteristic in the hysteresis loops.

Table 1. Bouc-Wen model characteristics

\begin{tabular}{lc}
\hline \multicolumn{1}{c}{ Parameters/Unit } & Values \\
\hline $\mathrm{C}_{0}\left(\mathrm{~N} . S . \mathrm{mm}^{-1}\right)$ & 1333 \\
$\mathrm{C}_{1 \mathrm{a}}\left(\mathrm{N} . \mathrm{S} \cdot \mathrm{mm}^{-1}\right)$ & 8.168 \\
$\mathrm{C}_{1 \mathrm{~b}}\left(\mathrm{~N} \cdot \mathrm{S} \cdot \mathrm{mm}^{-1} \cdot \mathrm{A}^{-1}\right)$ & 2.725 \\
$\alpha_{\mathrm{a}}\left(\mathrm{N} . \mathrm{mm}^{-1}\right)$ & 0 \\
$\alpha_{\mathrm{b}}\left(\mathrm{N} \cdot \mathrm{mm}^{-1}\right)$ & 1.723 \\
$\mathrm{k}_{0}\left(\mathrm{~N} \cdot \mathrm{mm}^{-1}\right)$ & 0.01072 \\
$\mathrm{k}_{1}\left(\mathrm{~N} \cdot \mathrm{mm}^{-1}\right)$ & 0.134 \\
$\mathrm{x}_{0}(\mathrm{~mm})$ & 114.9 \\
$\beta\left(\mathrm{mm}^{-2}\right)$ & 0.07 \\
$\mathrm{~A}$ & 300 \\
$\gamma / \mathrm{mm}^{2}$ & 0.07 \\
$\mathrm{n}$ & 2 \\
\hline
\end{tabular}




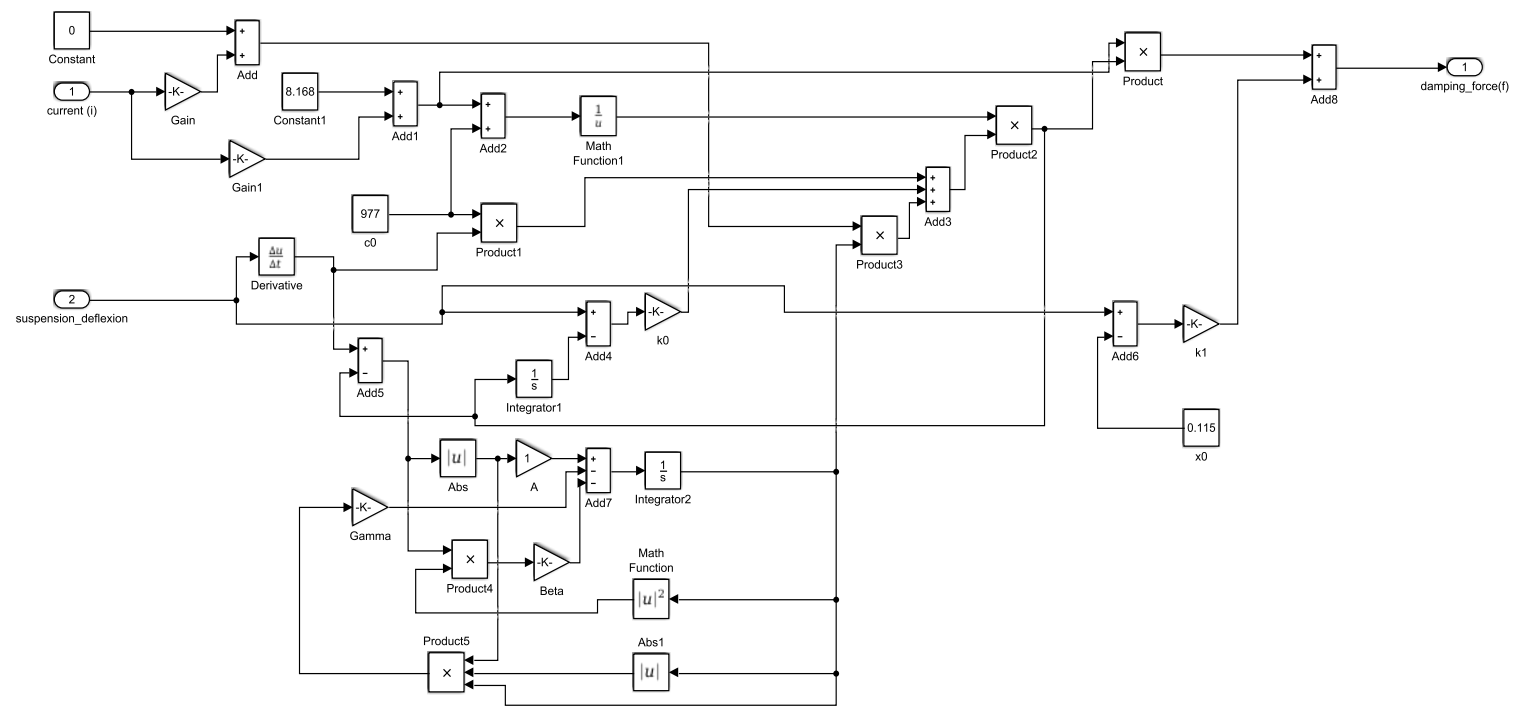

Figure 5. Simulink model of modified Bouc-Wen MR model

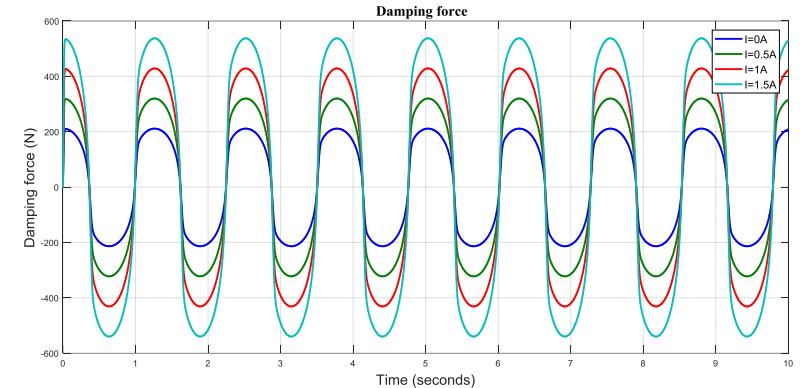

Figure 6. damping force versus time

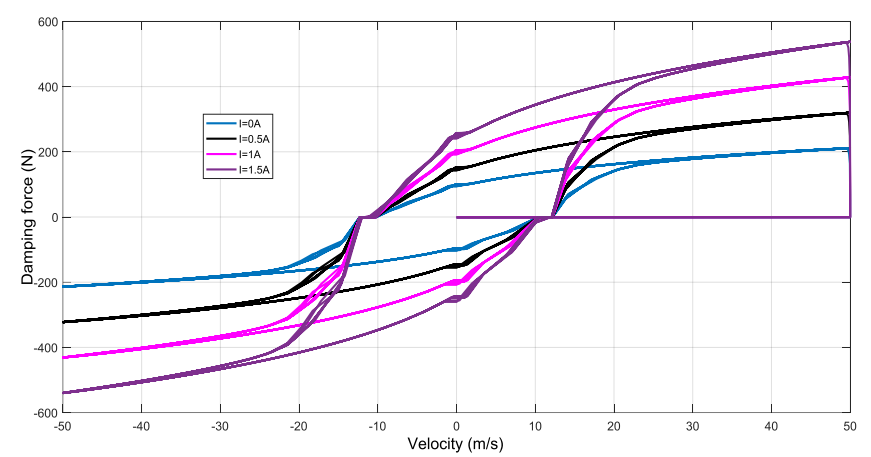

Figure 8. Damping force versus Velocity

\subsection{Quarter vehicle model}

In the study and investigation of vehicle suspension, linear quarter vehicle is very important in modeling car dynamic systems. Dynamic model of quarter model considers the vibration movement of wheel and chassis and ignore roll vibration and the pitch [12]. It is formed by sprung and unsprung mass bodies, shock absorber tires. Sprung mass is sustained above suspension system. Convention 2DOF two degree of freedom of quarter vehicle semiactive suspension model focuses on vehicle

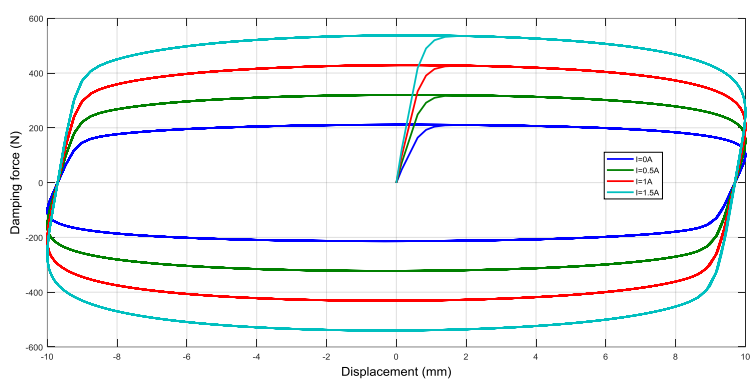

Figure 7. damping force vs Displacement

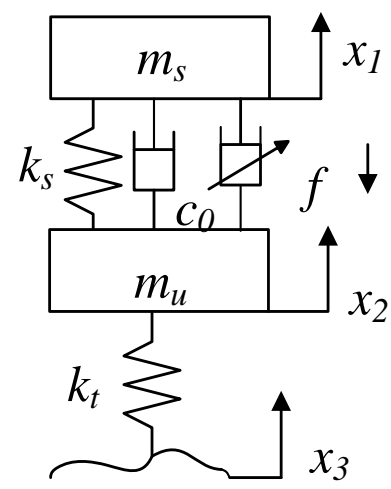

Figure 9. Quarter car model

vibration in the vertical way. The equation of motions model is obtained by adding all acting vertical forces on the unsprung masses and sprung masses. In the quarter-vehicle model suspension $m_{s}$ will be defined as the sprung mass, while axles and tire and are stated by the unsprung mass $m_{u}$. As it indicated in the Fig. 9, shock absorber, the spring and an adjustable force provider device situated between the sprung and unsprung masses forms suspension. By considering the quarter car model, the design and implementation of full car model might be 
expanded. The performance of this model increases road holding by keeping the ride comfort of occupants.

$\left\{\begin{array}{c}m_{s} \ddot{x} 1+k_{s}\left(x_{1}-x_{2}\right)+c_{0}\left(\dot{x}_{1}-\dot{x}_{2}\right)-f=0 \\ m_{u} \ddot{x}_{2}-k_{s}\left(x_{1}-x_{2}\right)-c_{0}\left(\dot{x}_{1}-\dot{x}_{2}\right)+k_{t}\left(x_{2}-x_{3}\right)+f=0\end{array}\right.$ freedom can be obtained:

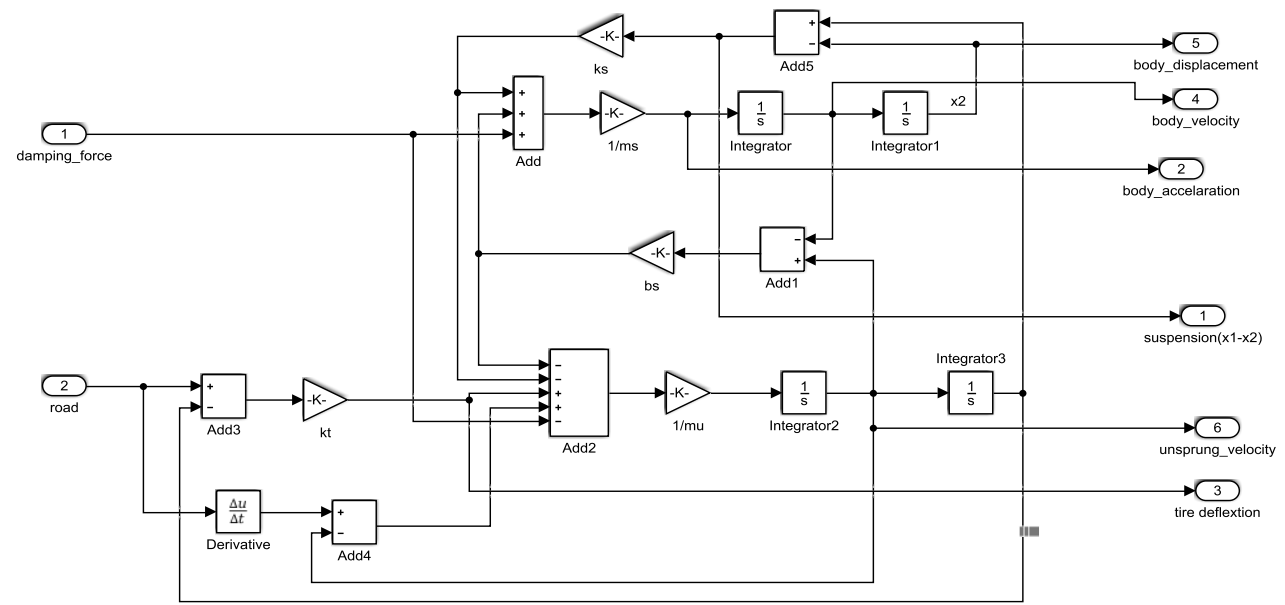

Figure 10. Simulink model of quarter semi-active suspension model

Where $\mathrm{m}_{\mathrm{s}}$ defines sprung mass, $\mathrm{k}_{\mathrm{s}}$ is the rigidity of the suspension spring, $т и$ denotes the unsprung mass $f$ is the adjustable damping force, $\mathrm{k}_{\mathrm{t}}$ denotes the tire rigidity $b t$ is tire damping coefficients. $c_{0}$ defines the coefficient of passive suspension damper, $x_{i}$ is the displacement of vehicle body mass, $x_{2}$ is the displacement of the unsprung mass, and $x_{3}$ is the uneven road disturbance $x_{3}$. Table 2 and Fig. 10 shows quarter car parameters and its values.

Table 2. Passive suspension parameters

\begin{tabular}{lc}
\hline \multicolumn{1}{c}{ Parameters } & Values \\
\hline Sprung mass $\left(m_{s}\right)$ & $280 \mathrm{~kg}$ \\
Unsprung mass $\left(m_{u}\right)$ & $28 \mathrm{~kg}$ \\
Stiffness coefficient $\left(k_{s}\right)$ & $275358 \mathrm{~N} / \mathrm{m}$ \\
Tire stiffness coefficient $\left(k_{t}\right)$ & $21465 \mathrm{~N} / \mathrm{m}$ \\
Damping coefficient $\left(c_{0}\right)$ & $1300 \mathrm{~N} /(\mathrm{m} / \mathrm{s})$ \\
\hline
\end{tabular}

As it is shown the Fig. 10, is the Simulink model of quarter car dynamic is established based on equation 8 .

\subsubsection{Semi-active suspension control model}

Semi- active suspension control based on MR damper system is composed by 2 controllers: a system controller and a damper controller, current driver, MR damper and quarter car model. The main objective of system controller
Based on Newton's second law of motion, the differential equation of $1 / 4$ vehicle semi-active suspension mechanism with 2 degrees of

is generated the desired damping force. The second controller serves on controlling the voltage to be applied to the current driver to track the desired damping force. The damping force provided by MR damper is fed to the vehicle dynamics to attenuate the vibration caused by uneven road [13] is shown in Fig. 11 and Fig. 16.

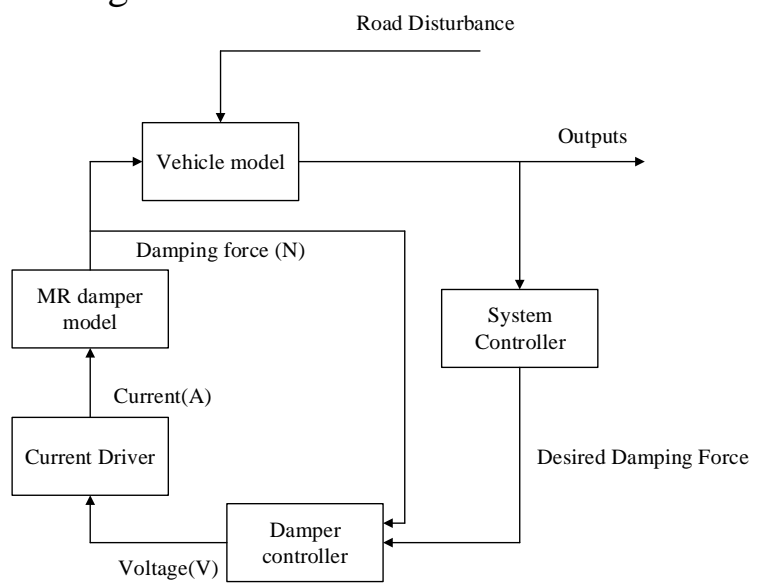

Figure 11. Block diagram of semi-active suspension system

\subsubsection{System controller}

In this control strategy of semi-active suspension fuzzy logic controller has been utilized to track the desired damping force. Here it is used to control damping force of suspension system. Fuzzy logic algorithm controls many loops variation in various non-linear systems. On this model (Fig.12) it has two inputs, 
suspension deflection and suspension velocity. It computes those inputs and provides the desired damping force based on inference rules subjected on it, the figures below explain the process of fuzzy logic, these control systems embed the human as thinking through the application of fuzzy configurations and linguistic variables related by a configuration of IF-THEN fuzzy rules as indicated in table 3 and Fig. 13. In this model, triangular shaped membership functions (MFs), are utilized to represent the input variables, which are suspension deflection and suspension velocity.

Table 3. Fuzzy inference rules

\begin{tabular}{cccccccc}
\hline $\begin{array}{c}\text { Suspension deflection } \\
\text { velocity }\end{array}$ & PL & PM & PL & ZE & NS & NM & NL \\
\hline NL & PM & PS & ZE & NS & NS & NS & NM \\
NM & PM & PM & PS & NS & NM & NM & NM \\
NS & PL & PL & PM & NS & NM & NM & NB \\
ZE & PL & PL & PM & ZE & NM & NL & NB \\
PS & PL & PM & PM & PS & NM & NL & NB \\
PM & PM & PM & PM & PS & NS & NM & NM \\
PL & PM & PS & PS & PS & ZE & NS & NM \\
\hline
\end{tabular}

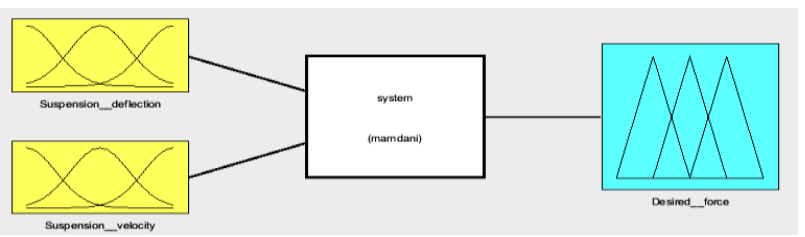

Figure 12. Fuzzy controller

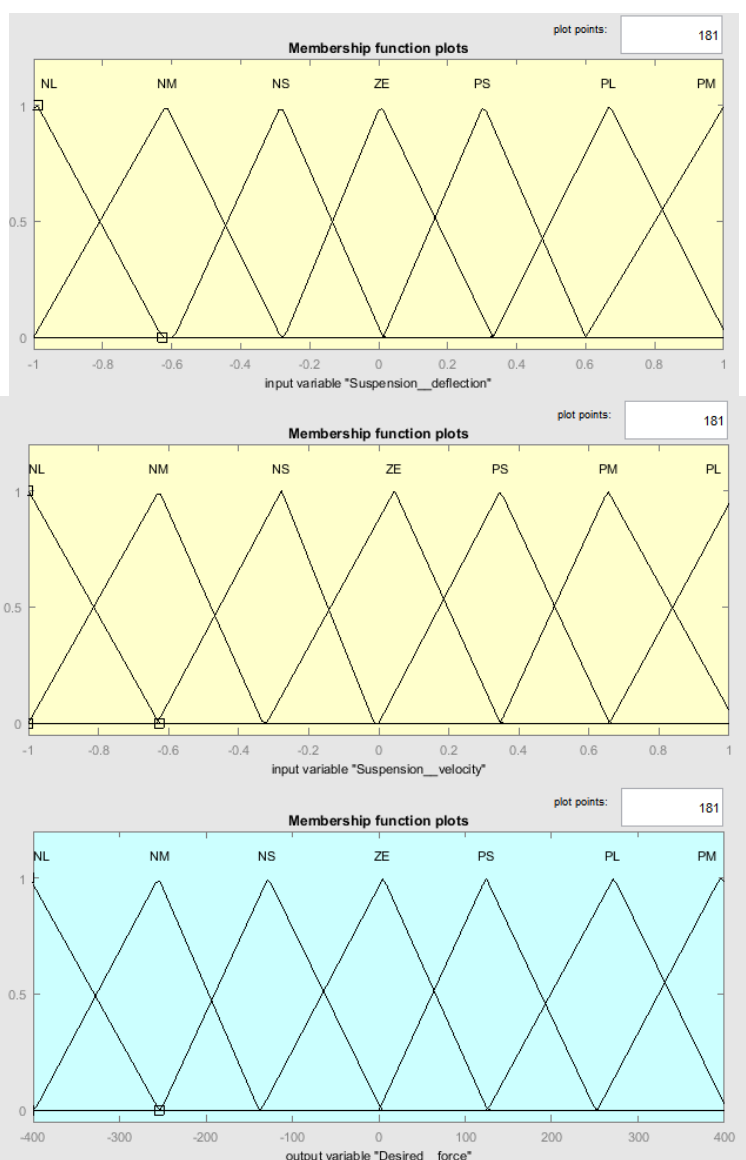

Figure 13. Membership functions (MFs) for suspension deflection, suspension velocity and desired Force
The fuzzy controller has seven linguistic variables for each input: NL, negative large, NM negative medium, NS negative small, ZE zero, PS positive Small, PM, positive medium and PL positive large.

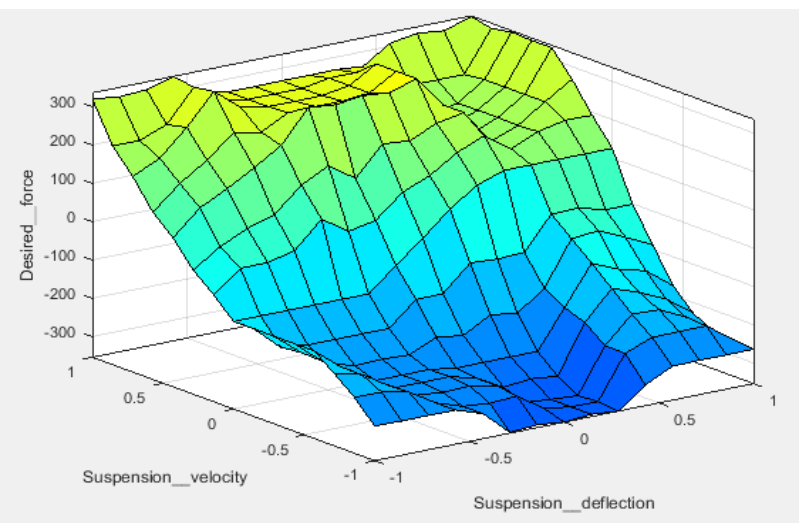

Figure 14. Fuzzy map

\subsubsection{Damper controller}

The role of damper controller is to provide a proper command of voltage to the current driver by tracking the desired damping force and actual damping. The equation below indicates control law of damper voltage.

$v=V_{\max } H\left[\left(f_{c}-f_{d}\right) f_{c} f_{d}\right]$

Where Vmax is denotes as the maximum voltage applied to the current driver related with saturation of the magnetic field in the MR damper $(\cdot)$ is the Heaviside step function, $f_{c}$ the desired damping force, $f_{d}$ the actual damping force. Fig. 15 is developed based on equation 9 . 


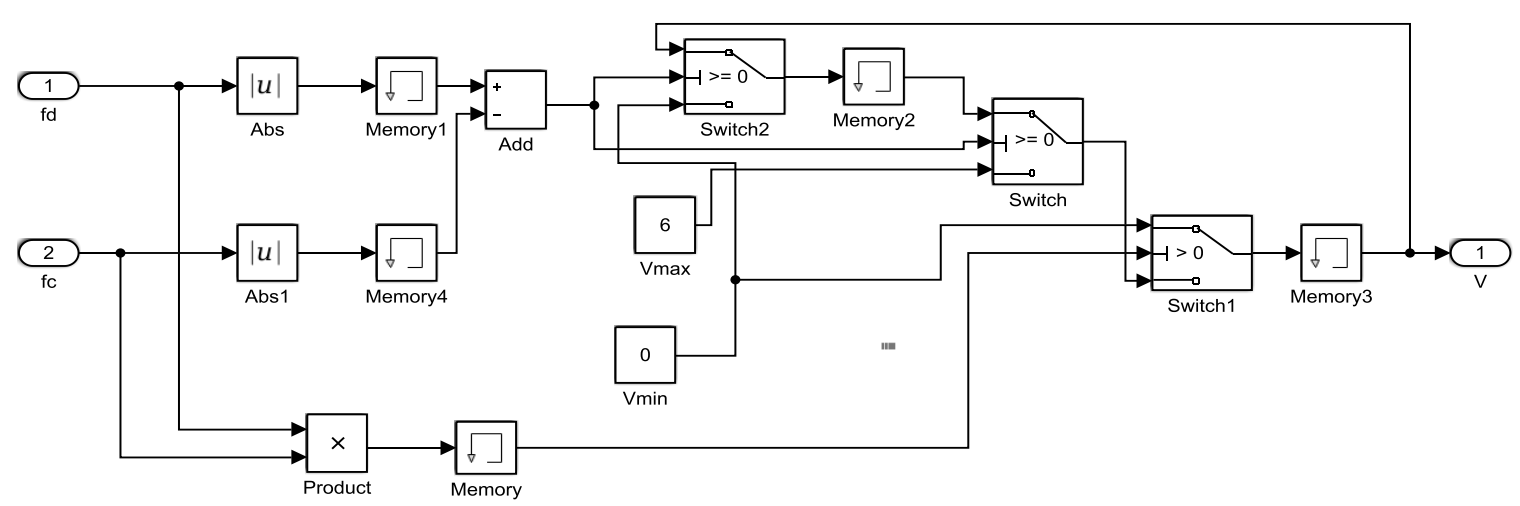

Figure 15. Voltage controller

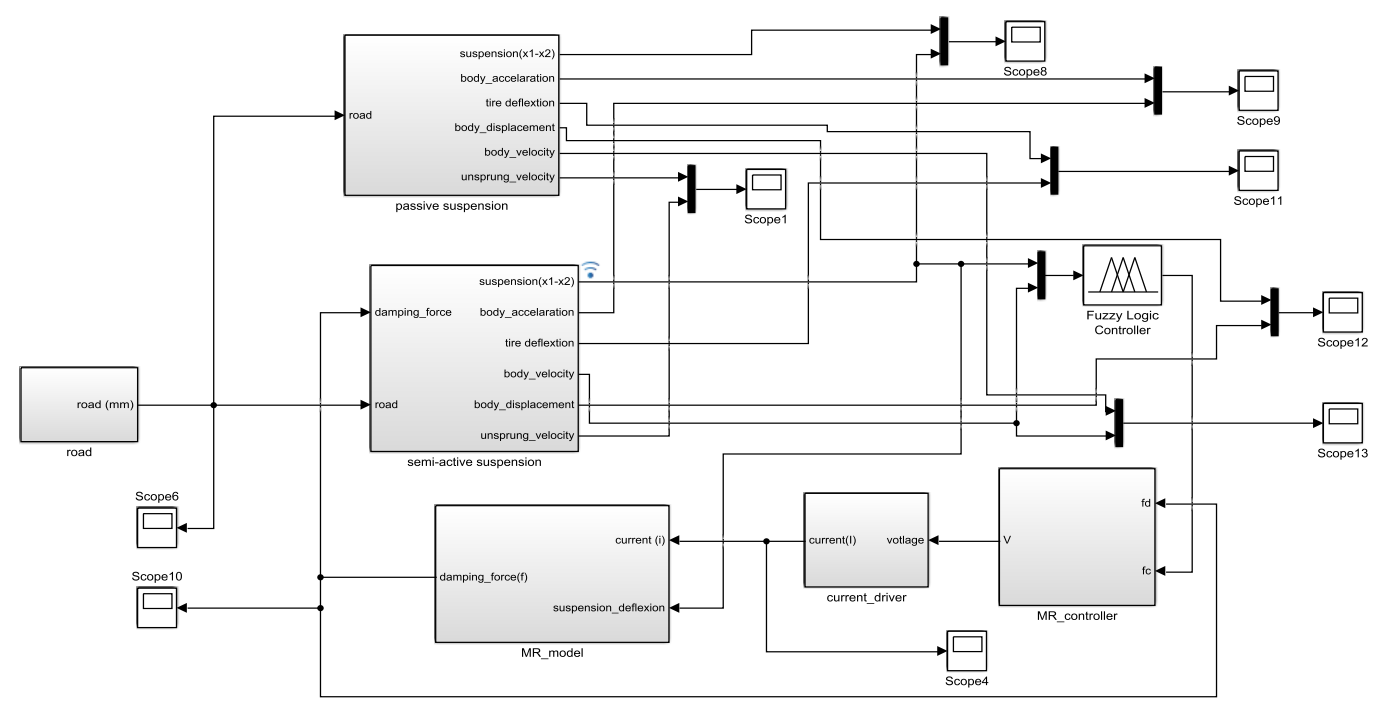

Figure 16. Voltage controller

The road model is composed by one bump with height of $0.08 \mathrm{~m}$ as it is shown in fig. 17 .

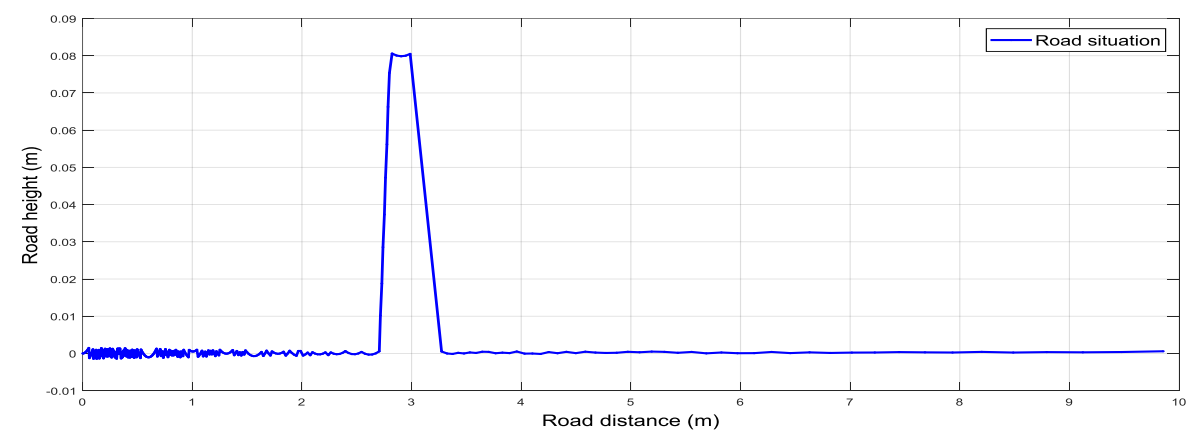

Figure 17. Road situation

\section{Results and Discussion}

The current applied to the MR damper varies between $0 \mathrm{~A}$ to $2.5 \mathrm{~A}$, Fig. 18, which produces the maximum damping force of $600 \mathrm{~N}$, fig. 10 the suspension deflection and body displacement of semi-active suspension, minimizes the amplitude and increases the response time compare to passive suspension system as it is shown in Fig. 20 and Fig. 21. The index of ride comfort is body displacement variation and index of road handling (stability) is suspension deflection variation. In this model, the ride comfort is greater compare to passive suspension and the suspension deflection has been also reduced compare to passive suspension. As the rate of suspension deflection defines the road holding; in this model, the road holding is achieved on the level of $33.94 \%$ The Fuzzy and damper controller design strategy has been analyzed for the semi-active system deflection and the results shows great improvement compare to the value gotten in passive system table 4 . 
Table 4. Root Mean Square comparison

\begin{tabular}{cccc}
\hline Parameters & Passive & Semi-active & $\begin{array}{c}\text { Improvement } \\
\text { percentage }\end{array}$ \\
\hline Body displacement $(\mathrm{m})$ & 0.0524 & 0.0465 & $11.25 \%$ \\
Suspension deflection(m) & 0.0218 & 0.0144 & $33.94 \%$ \\
\hline
\end{tabular}

Based on semi-active suspension in vehicle dynamic system model there is a possibility of reduction the odds issue between vehicle stability and ride comfort. In fact, the results of simulation show that road handling stability and vehicle drive comfort has been improved.

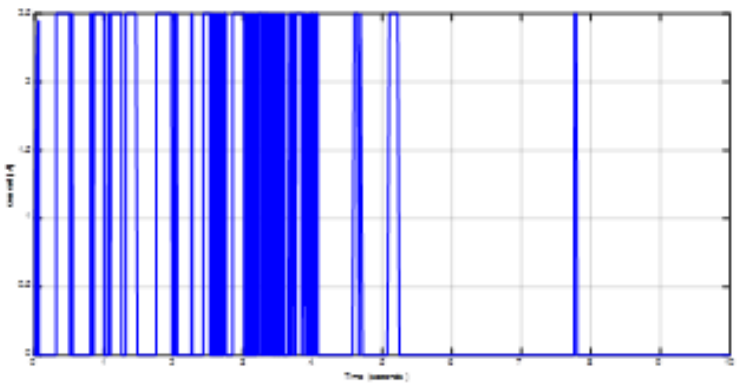

Figure 18. Current applied to MR damper (A)

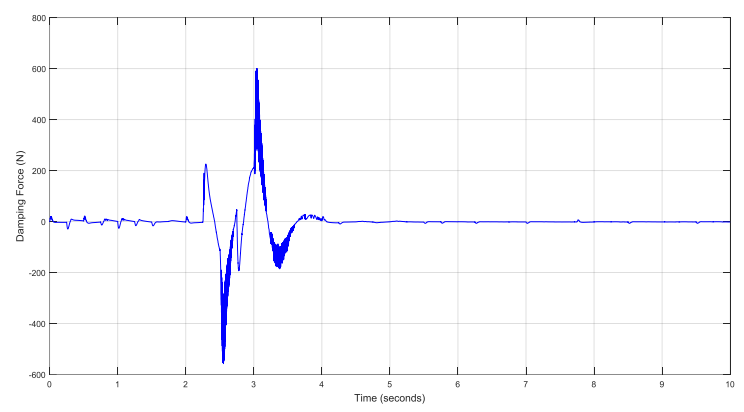

Figure 19. Damping force (N)

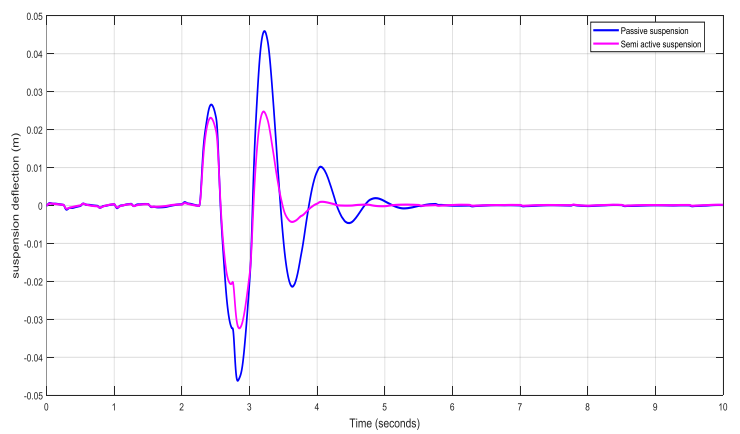

Figure 20. Suspension deflection

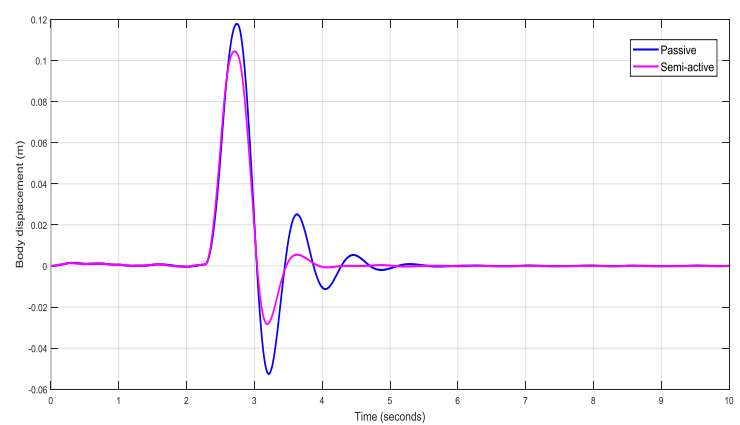

Figure 21. Body displacement

\section{Conclusion}

This research of fuzzy logic controller for semi active suspension based on MR damper has been composed by three many parties; road modeling, quarter vehicle model control and controller. Matlab/Simulink has been used to model and simulate the model. A road was composed by road straight surface and a bump. Quarter vehicle model and Bouc Wen model of MR damper have been modeled and simulated. The control strategies based on fuzzy logic and damper controller for tracking desired force have been used to control and monitor the damping force of MR damper. By considering vertical motion of quarter car model, mathematical equations of second law of Newton has been performed using a two degreeof-freedom model of the quarter car model for passive and semi active suspension system. Fuzzy controller design approach has been investigated for the semi-active system. Suspension deflection as well as body displacement has greatly minimized compare to passive suspension. In this research, the control strategy has verified through the simulation and comparison between passive and semi-active is the ideal situation. However, the real control may have some interference and uncertainty. Thus the validity of the control strategy still needs to be verified and optimize the performance of feedforward hardware test in the semi-active suspension system test bench.

\section{References}

[1] G. Priyandoko, M. Mailah, and H. Jamaluddin, "Vehicle active suspension system using skyhook adaptive neuro active force control," Mechanical systems and signal processing, vol. 23, pp. 855-868, 2009.

[2] L.-S. Jorge de-J, R. Morales-Menendez, and R. A. Ramirez-Mendoza, "Evaluation of on-off semi-active vehicle suspension systems by using the hardware-in-the-loop approach and the 
software-in-the-loop approach," Proceedings of the Institution of Mechanical Engineers, Part D: Journal of Automobile Engineering, p. $0954407013517222,2014$.

[3] Q. Guo and D. Hua, "Intelligent Control of Vehicle Magneto-Rheological SemiActive Suspension," Metallurgical \& Mining Industry, 2015.

[4] J. Rabinow, "The magnetic fluid clutch," Electrical Engineering, vol. 67, pp. 1167-1167, 1948.

[5] M.-S. Seong, S.-B. Choi, and K.-G. Sung, "Control Strategies for Vehicle Suspension System Featuring Magnetorheological (MR) Damper," in Vibration Analysis and Control-New Trends and Developments, ed: InTech, 2011.

[6] R. Stanway, J. Sproston, and N. Stevens, "Non-linear modelling of an electrorheological vibration damper," Journal of Electrostatics, vol. 20, pp. 167-184, 1987.

[7] S. Guo, S. Yang, and C. Pan, "Dynamic modeling of magnetorheological damper behaviors," Journal of Intelligent material systems and structures, vol. 17, pp. 3-14, 2006.

[8] R. Bouc, "A mathematical model for hysteresis," Acta Acustica united with Acustica, vol. 24, pp. 16-25, 1971.

[9] Y.-K. Wen, "Method for random vibration of hysteretic systems," Journal of the engineering mechanics division, vol. 102, pp. 249-263, 1976.

[10] B. Spencer Jr, S. Dyke, M. Sain, and J. Carlson, "Phenomenological model for magnetorheological dampers," Journal of engineering mechanics, vol. 123, pp. 230-238, 1997.

[11] Y. Shen, M. Golnaraghi, and G. Heppler, "Analytical and experimental study of the response of a suspension system with a magnetorheological damper," Journal of intelligent material systems and structures, vol. 16, pp. 135-147, 2005.

[12] C. C. De Wit and P. Tsiotras, "Dynamic tire friction models for vehicle traction control," in Decision and Control, 1999. Proceedings of the 38th IEEE Conference on, 1999, pp. 3746-3751.
[13] D. Wang and W. H. Liao, "Magnetorheological fluid dampers: a review of parametric modelling," Smart materials and structures, vol. 20, p. 023001, 2011. 